\title{
Deep venous thrombosis among diabetic patients in King Abdulaziz University (KAU) Hospital, Jeddah, Kingdom of Saudi Arabia
}

Hanan Khalid Alotaibi ${ }^{1}$, Nagah Mohamed Abo el-Fetoh ${ }^{2}$, Aseel MenwerAlanazi ${ }^{1}$, Omar Ayed Alanazi ${ }^{1}$, Abdullah Barghash Alanazi ${ }^{1}$, Mohammed Ali Alhowaish ${ }^{1}$, Hussam Saeed Busays Alzahrani ${ }^{1}$, Mashael Abdullah

Alshammari ${ }^{3}$, Rawan Fulayyih ALrashidi ${ }^{3}$, Thikra Mohammed Alblowi ${ }^{3}$, Sarah Jemal Alqahtani ${ }^{3}$, Fatin Salem Almaashi $^{3}$

${ }^{1}$ Intern, Faculty of Medicine, Northern Border University, Arar, Kingdom of Saudi Arabia

${ }^{2}$ Associate professor, Community Medicine Department, Faculty of Medicine, Northern Border University, Arar, Kingdom of Saudi Arabia

${ }^{3}$ Medical Intern, Faculty of Medicine, Hail University, Hail, Kingdom of Saudi Arabia

Type of article: Original

\begin{abstract}
Background: Deep venous thrombosis (DVT) is a major cause of morbidity and mortality among hospitalized patients worldwide and, simultaneously, the most preventable. Studies revealed several risk factors of deep venous thrombosis in hospitalized patients.

Objective: to identify frequency and factors associated with occurrence of deep venous thrombosis among diabetic patients referred to King Abdulaziz University (KAU) Hospital, Jeddah, Kingdom of Saudi Arabia.

Methods: This cross-sectional hospital-based study was conducted from June to December, 2016. All diabetic patients referred to the hospital departments and who were suspected to have deep venous thrombosis (DVT) and subjected to Doppler examination were included in the study. A questionnaire was designed to obtain data about deep venous thrombosis frequency among participants and factors associated with the development of deep venous thrombosis among them. Data was collected through face to face interviews with patients included in the study. We used SPSS version 16 for data analysis through descriptive statistics and Chi-square test.

Results: DVT was detected in $14.7 \%$ of the examined patients. There were significant and positive associations between age and DVT $\left(\mathrm{X}^{2}=10.13, \mathrm{p}=0.03\right)$ and between ischemic heart disease and DVT $\left(\mathrm{X}^{2}=1.628, \mathrm{p}=0.043\right)$ with the development of deep venous thrombosis among the studied patients. On the other hand, gender, other comorbidities, history of previous DVT, being bed ridden and using orthopedic casting were not significantly associated with the occurrence of deep venous thrombosis among the participants.

Conclusion: DVT development rate among the participants was $14.7 \%$. Aging was significantly associated with DVT occurrence. Most of the studied factors and comorbidities had no significant role in DVT development among participants and only ischemic heart disease was significantly associated with DVT development.
\end{abstract}

Keywords: DVT, Diabetes, Risk factor

\section{Introduction}

Deep venous thrombosis (DVT) is a major cause of morbidity and mortality among hospitalized patients worldwide and, simultaneously, the most preventable $(1,2)$. It is a condition caused by the formation of a thrombus in the venous system, preceded or followed by an inflammatory response of the vessel wall. When part of the thrombus breaks off, it can migrate through the circulatory system to the pulmonary artery, resulting in a pulmonary embolism $(3,4)$. Guidelines for prophylaxis of venous thrombosis have existed for over 15 years, however, these guidelines are completely used in less than $55 \%$ of indications (5). As a result, in every six cases of thromboembolism only one case could be avoided (6), and morbidity and mortality associated with DVT is still high among hospitalized patients $(7,8)$. Studies revealed several risk factors of deep venous thrombosis in hospitalized patients (7). Diabetes mellitus

Corresponding author:

Hanan Khalid Alotaibi, Faculty of Medicine, Northern Border University, Arar, Kingdom of Saudi Arabia.

Tel.: +966559042805, Email: hanan.alot@hotmail.com

Received: July 22, 2017, Accepted: August 23, 2017, Published: September 2017

iThenticate screening: August 23, 2017, English editing: September 08, 2017, Quality control: September 09, 2017

(C) 2017 The Authors. This is an open access article under the terms of the Creative Commons Attribution-NonCommercialNoDerivs License, which permits use and distribution in any medium, provided the original work is properly cited, the use is non-commercial and no modifications or adaptations are made. 
is a reported risk factor for venous thrombosis (9-11) and pulmonary embolism (12), and it was estimated that there is a 1.4-fold increased risk of venous thrombosis for persons with diabetes (13). This could be attributed to the frequent hospitalization of diabetic patients for major surgery or acute medical illness (9). In addition, diabetes may be complicated by microvascular occlusive disease. The same process that causes such arterial vascular disease among diabetics has been suggested to result in venous thrombosis (11). However, other studies failed to find an association between diabetes and venous thrombosis $(13,14)$. Furthermore, extensive venous thrombosis could occur as a rare complication of diabetic ketoacidosis which emphasizes the need for deep venous thrombosis prophylaxis therapy in the management of these patients (15). Other factors have been documented to increase the risk of venous thrombosis including increasing age, paralysis or prolonged immobility, previous DVT, congestive heart failure, acute infection, pregnancy or puerperium, cancer and its treatment, dehydration, varicosities, rheumatological disease and nephrotic syndrome. Oral contraceptive pills, especially those that contain thirdgeneration progestins, also predispose to venous thrombosis $(7,16)$. In addition, obesity, hypertension, low lowdensity lipoprotein (LDL) levels, and high triglyceride levels may play a role in venous thrombosis occurrence (13). Detection of suspected cases of deep venous thrombosis is difficult and sometimes these cases may be missed. Primary prevention of deep venous thrombosis is one of the most important means in the management of high risk patients due to the high economic burden and increased morbidity and mortality associated with venous thrombosis $(7,17)$. So, this study was conducted to identify frequency and factors associated with occurrence of deep venous thrombosis among diabetic patients referred to King Abdulaziz University (KAU) hospital, Jeddah, Kingdom of Saudi Arabia.

\section{Material and Methods}

\subsection{Study design, setting, and participants}

The current study was a hospital based cross-sectional study conducted in KAU hospital, Jeddah, Kingdom of Saudi Arabia. The emergency, inpatients and outpatients departments in KAU hospital were reviewed for a period of 6 months (from June to December, 2016). All diabetic patients referred or admitted to the hospital departments and who were clinically suspected to have deep venous thrombosis (DVT) (paralysis, paresis or recent plaster immobilization of the lower extremities, localized tenderness along the distribution of the deep venous system, entire leg swollen, calf swelling at least $3 \mathrm{~cm}$ larger than asymptomatic side, calf pain, pitting edema confined to the symptomatic leg, erythema and warmth in the lower extremities or previously documented DVT) and subjected to Doppler examination were included in the study. Exclusion criteria included patients who refused to participate in the study and emotionally unstable persons.

\subsection{Data Collection Method}

A questionnaire was designed to obtain data about deep venous thrombosis frequency among diabetic patients referred to KAU hospital, Jeddah, Kingdom of Saudi Arabia and factors associated with the development of deep venous thrombosis among them. Data was collected through face to face interviews with patients included in the study. The questionnaire included questions about age and sex of participants, department, site and result of Doppler examination, whether being bed ridden or using orthopedic casting and the history of previous deep venous thrombosis. In addition, the questionnaire included inquiries about presence of comorbidities such as hypertension, ischemic heart disease, and cancer in the participating patients.

\subsection{Ethical consideration}

Before starting data collection, ethical approval was obtained from the Research Ethics Committee of Faculty of Medicine, King Abdulaziz University. During the data collection stage, informed consent was secured from each participant. The questionnaires used in data collection were anonymous and confidentiality of data was assured.

\subsection{The statistical analysis}

The statistical analysis was carried out using SPSS version 16 (SPSS Inc., Chicago, Illinois, USA). Sample characteristics were summarized as numbers and percentages for categorical variables. Chi-square test was used for comparing qualitative variables. A 5\% level was chosen as a level of statistical significance in all statistical tests used in the study.

\section{Results}

The current study included 224 diabetic patients admitted to the hospital departments and were clinically suspected to have deep venous thrombosis and subjected to Doppler examination during the study period. Regarding age, 139 $(62.1 \%)$ of the participants were $\geq 60$ years old and only $3(1.3 \%)$ were younger than 30 years old. Males 
represented $51.8 \%$ of the studied patients. More than half (56.7\%) of the studied patients were admitted to inpatients departments of the hospital and more than one third (34.8\%) of them were interviewed in the emergency department. Regarding the site of Doppler examination, $56.2 \%$ of the participants were subjected to examination of the right lower limb, $42.4 \%$ were subjected to left lower limb examination and bilateral examination was done only for $1.3 \%$ of the studied patients (Table 1). Regarding development of deep venous thrombosis (DVT) among the studied patients, according to the results of Doppler examination, DVT was detected in $14.7 \%$ of the examined patients and $85.3 \%$ of them were negative. Table 2 shows distribution of the studied patients regarding the presence of comorbidities, history of previous DVT, using orthopedic casting, and whether the patient was bed ridden or elderly. As illustrated by the presented data, $62.1 \%$ of the participants were elderly ( $\geq 60$ years old), $8.9 \%$ of them were bed ridden and most of them (99.1) were not using orthopedic casting. Only $1.8 \%$ of the studied patients reported a history of previous DVT. As regards comorbidities, $73.2 \%$ of the participants were hypertensive, $12.9 \%$ had ischemic heart disease and $2.7 \%$ had malignancies (whether primary or metastasis). As shown in Table (3), old age and the presence of ischemic heart disease significantly affected the development of deep venous thrombosis among the studied patients ( $\mathrm{p}=0.03, \mathrm{p}=0.043$ respectively). On the other hand, other comorbidities such as hypertension and cancer were not significantly associated with the occurrence of deep venous thrombosis among the participants $(\mathrm{p}=0.381, \mathrm{p}=0.129$ respectively). No significant gender differences were observed between patients who developed DVT and those who were negative by Doppler examination $(\mathrm{p}=0.439)$. Furthermore, the other investigated factors such as history of previous DVT, being bed ridden and using orthopedic casting were not significantly associated with the development of deep venous thrombosis among the studied patients.

Table 1. Sex, age group, patient's department and site of Doppler examination of the studied patients, KAU hospital, Jeddah, $2016(\mathrm{n}=224)$

\begin{tabular}{|l|l|l|l|}
\hline Variable & $\mathrm{n}$ & $\%$ \\
\hline Sex & Female & 108 & 48.2 \\
\cline { 2 - 4 } & Male & 116 & 51.8 \\
\hline \multirow{4}{*}{ Age (years); 54.78 \pm 19.8} & $<30$ & 3 & 1.3 \\
\cline { 2 - 4 } & $30-40$ & 10 & 4.5 \\
\cline { 2 - 4 } & $40-50$ & 20 & 8.9 \\
\cline { 2 - 4 } & $50-60$ & 52 & 23.2 \\
\cline { 2 - 4 } & $>60$ & 139 & 62.1 \\
\hline Patient's department & Emergency & 78 & 34.8 \\
\cline { 2 - 4 } & In patient & 127 & 56.7 \\
\cline { 2 - 4 } & Out patient & 19 & 8.5 \\
\hline Site of Doppler examination & Bilateral & 3 & 1.3 \\
\cline { 2 - 4 } & Left & 95 & 42.4 \\
\cline { 2 - 4 } & Right & 126 & 56.2 \\
\hline
\end{tabular}

Table 2. Distribution of the studied patients regarding suspected risk factors, KAU hospital, Jeddah, 2016(n=224)

\begin{tabular}{|l|l|l|l|}
\hline Variable & \multicolumn{1}{|l|}{$\mathrm{n}$} & $\%$ \\
\hline Being elderly & Yes & 139 & 62.1 \\
\cline { 2 - 4 } & No & 85 & 37.9 \\
\hline \multirow{3}{*}{ Being bed ridden } & Yes & 20 & 8.9 \\
\cline { 2 - 4 } & No & 204 & 91.1 \\
\hline Orthopedic casting & Yes & 2 & 0.9 \\
\cline { 2 - 4 } & No & 222 & 99.1 \\
\hline \multirow{2}{*}{ Hypertension } & Yes & 164 & 73.2 \\
\cline { 2 - 4 } & No & 60 & 26.8 \\
\hline \multirow{2}{*}{ Ischemic heart disease (IHD) } & Yes & 29 & 12.9 \\
\cline { 2 - 4 } & No & 195 & 87.1 \\
\hline \multirow{2}{*}{$\begin{array}{l}\text { Cancers (primary or } \\
\text { metastasis) }\end{array}$} & Yes & 6 & 2.7 \\
\hline \multirow{2}{*}{ Previous DVT } & No & 218 & 97.3 \\
\hline \multirow{2}{*}{ Other factors } & Yes & 4 & 1.8 \\
\cline { 2 - 4 } & No & 220 & 98.2 \\
\hline & Yes & 17 & 7.6 \\
\cline { 2 - 4 } & No & 207 & 92.4 \\
\hline
\end{tabular}


http://www.ephysician.ir

Table 3. The relationship between presence of DVT and suspected risk factors in the studied diabetic cases, KAU hospital, Jeddah, $2016(\mathrm{n}=224)$

\begin{tabular}{|l|l|l|l|l|l|}
\hline \multirow{2}{*}{ Risk factors } & \multicolumn{2}{|l|}{ Deep venous thrombosis (DVT) } & Total $(\mathrm{n}=224)$ & \multirow{2}{*}{ Chi-square } & p-value \\
\cline { 2 - 4 } & Negative $(\mathrm{n}=191)$ & Positive (n=33) & & & \\
\cline { 2 - 4 } & $\mathrm{n}(\%)$ & $\mathrm{n}(\%)$ & $\mathrm{n}(\%)$ & & \\
\hline Gender (male) & $98(51.3)$ & $18(54.5)$ & $116(51.8)$ & 0.11 & 0.439 \\
\hline Being elderly & $119(62.3)$ & $20(60.6)$ & $139(62.1)$ & 10.13 & 0.03 \\
\hline Hypertension & $141(73.8)$ & $23(69.7)$ & $164(73.2)$ & 0.442 & 0.381 \\
\hline Bed ridden & $16(8.4)$ & $4(12.1)$ & $20(8.9)$ & 0.485 & 0.337 \\
\hline IHD & $27(14.1)$ & $2(6.1)$ & $29(12.9)$ & 1.628 & 0.043 \\
\hline Cancers & $3(1.6)$ & $3(9.1)$ & $6(2.7)$ & 6.10 & 0.129 \\
\hline Previous DVT & $4(2.1)$ & $0(0.0)$ & $4(1.8)$ & 0.701 & 0.521 \\
\hline Orthopedic cast & $2(1.0)$ & $0(0.0)$ & $2(0.9)$ & 0.34 & 0.72 \\
\hline Others & $16(8.4)$ & $1(3.0)$ & $17(7.6)$ & 1.14 & 0.25 \\
\hline
\end{tabular}

\section{Discussion}

Deep venous thrombosis is a common complication not only in surgical but also in acutely ill hospitalized medical patients 918). In our study, 224 diabetic patients who were admitted to the hospital departments and were clinically suspected to have deep venous thrombosis and subjected to Doppler examination during the study period were interviewed to identify frequency and factors associated with occurrence of deep venous thrombosis among them. The current study revealed that, according to the results of Doppler examination, $14.7 \%$ of the examined patients had DVT and $85.3 \%$ of them were negative. This frequency was lower than the findings of several studies in which one study (3) found that DVT frequency among the studied diabetic patients was $31.6 \%$ and another study (10) reported that the DVT frequency among diabetic patients was $60.7 \%$. A higher DVT development frequency among diabetic patients (88.7\%) was observed by another study (19). A study by (20) to explore the relationship of metformin therapy and the subsequent development of DVT among diabetic patients revealed that $48 \%$ of diabetic patients who were not using metformin developed DVT in comparison to only $26.7 \%$ of those who were on metformin therapy. On the other hand, the findings of the current study were much higher than the results reported by (21) who found that DVT frequency among the participating diabetic cancer patients was only $4.5 \%$. According to the results of the present study, old age was significantly associated with the development of DVT among the studied patients. On the other hand, no significant difference was found between patients who developed DVT and those whose Doppler examination was negative regarding gender. In support of our findings, other studies, found a highly significant association between age and DVT development while gender was not significantly associated with DVT occurrence $(3,14,20,22,23)$. Contrarily, another study found no significant association between age and the development of DVT (24). Regarding the studied comorbidities among the participants in the current study, the most frequent comorbidity among patients with Doppler confirmed DVT was hypertension $(69.7 \%)$ which is consistent with the findings of another study (25) where hypertension was the most frequent comorbidity (50\%) in the ultrasound confirmed DVT patients. Hypertension and cancer were not significantly associated with the occurrence of deep venous thrombosis among the participants in the current study. These findings are in line with what was reported by two other studies $(20,22)$ where both comorbidities had no significant effect on DVT development in the studied population. The current study found that ischemic heart disease was significantly associated with DVT development. This was supported by the findings of another study (26) that found a significant association between heart diseases and myocardial infarction and the risk of venous thromboembolism. Contrary to our results, another study (22) found that there was no significant relation between angina pectoris or myocardial infarction and the development of DVT among the participating patients. History of previous DVT was not significantly associated with the development of DVT among participants of the current study, which is inconsistent with the findings of another study (24) that revealed a highly significant association between the current diagnosis of DVT and the history of previous DVT $(\mathrm{p} \leqslant 0.0001)$. The current study found no significant association between being bedridden and the development of DVT among the studied patients. These findings were inconsistent with the results revealed by two other studies $(27,28)$ where being bedridden was among the independent risk factors of DVT. The present study has some limitations. First, the small sample size, therefore additional investigation in a larger sample size is required. Further, as a cross-sectional survey, causality cannot be tested. 


\section{Conclusions}

The current study revealed that the frequency of DVT development among the studied diabetic patients was $14.7 \%$, and $85.3 \%$ of them were negative. Increased age was significantly associated with the development of deep venous thrombosis among the studied patients while gender had no significant effect. Most of the studied factors and comorbidities had no significant role in DVT development among the study participants and only ischemic heart disease was significantly associated with the development of DVT.

\section{Acknowledgments:}

The authors would like to acknowledge all patients participating in the study and the hospital health workers who motivated them to take part in the study.

\section{Conflict of Interest:}

There is no conflict of interest to be declared.

Authors' contributions:

All authors contributed to this project and article equally. All authors read and approved the final manuscript.

\section{References:}

1) Okuhara A, Navarro TP, Procópio RJ, Bernardes RDC, Oliveira LDCC, Nishiyama MP. Incidence of deep vein thrombosis and quality of venous thromboembolism prophylaxis. Rev Col Bras Cir. 2014; 41(1): 02-6. doi: 10.1590/S0100-69912014000100002. PMID: 24770766.

2) Geerts WH, Bergqvist D, Pineo GF, Heit JA, Samama CM, Lassen MR, et al. Prevention of venous thromboembolism: American College of Chest Physicians evidence-based clinical practice guidelines (8th Edition). Chest journal. 2008; 133(6_suppl): 381S-453S. doi: 10.1378/chest.08-0656. PMID: 18574271.

3) García-Raso A, Sillero PL. Elevated body fat is a risk factor for venous thromboembolism and thrombotic complications. Epidemiology Reports. 2014; 2(1): 3. doi: 10.7243/2054-9911-2-3.

4) Cohen AT, Agnelli G, Anderson FA, Arcelus JI, Bergqvist D, Brecht JG, et al. Venous thromboembolism (VTE) in Europe. The number of VTE events and associated morbidity and mortality. Thromb Haemost. 2007; 98(4): 756-64. PMID: 17938798.

5) Caprini JA, Tapson VF, Hyers TM, Waldo AL, Wittkowsky AK, Friedman R, et al. Treatment of venous thromboembolism: adherence to guidelines and impact of physician knowledge, attitudes, and beliefs. J Vasc Surg. 2005; 42(4): 726-33. doi: 10.1016/j.jvs.2005.05.053. PMID: 16242561.

6) Arnold DM, Kahn SR, Shrier I. Missed opportunities for prevention of venous thromboembolism: an evaluation of the use of thromboprophylaxis guidelines. Chest. 2001; 120(6): 1964-71. doi: 10.1378/chest.120.6.1964. PMID: 11742929.

7) Awolesi D, Naidoo M, Cassimjee MH. The profile and frequency of known risk factors or comorbidities for deep vein thrombosis in an urban district hospital in KwaZulu-Natal. Southern African Journal of HIV Medicine. 2016; 17(1): 1-5. doi: 10.4102/sajhivmed.v17i1.425.

8) Geerts WH, Pineo GF, Heit JA, Bergqvist D, Lassen MR, Colwell CW, et al. Prevention of venous thromboembolism: the Seventh ACCP Conference on Antithrombotic and Thrombolytic Therapy. Chest. 2004; 126(3_suppl): 338S-400S. doi: 10.1378/chest.126.3_suppl.338S. PMID: 15383478 .

9) Heit JA, Leibson CL, Ashrani AA, Petterson TM, Bailey KR, Melton LJ. Is diabetes mellitus an independent risk factor for venous thromboembolism? Arterioscler Thromb Vasc Biol. 2009; 29(9): 1399405. doi: 10.1161/ATVBAHA.109.189290. PMID: 19542020, PMCID: PMC2735343.

10) Petrauskiene V, Falk M, Waernbaum I, Norberg M, Eriksson JW. The risk of venous thromboembolism is markedly elevated in patients with diabetes. Diabetologia. 2005; 48(5): 1017-21. doi: 10.1007/s00125-0051715-5. PMID: 15778859.

11) Lowe G. Common risk factors for both arterial and venous thrombosis. Br J Haematol. 2008; 140(5): 48895. doi: 10.1111/j.1365-2141.2007.06973.x. PMID: 18275426.

12) Movahed MR, Hashemzadeh M, Jamal MM. The prevalence of pulmonary embolism and pulmonary hypertension in patients with type II diabetes mellitus. Chest. 2005; 128(5): 3568-71. doi: 10.1016/S00123692(15)52932-2.

13) Ageno W, Becattini C, Brighton T, Selby R, Kamphuisen PW. Cardiovascular risk factors and venous thromboembolism. Circulation. 2008; 117(1): 93-102. doi: 10.1161/CIRCULATIONAHA.107.709204. PMID: 18086925. 
14) Holst AG, Prescott E. Risk Factors for Venous Thromboembolism: Results From the Copenhagen City Heart Study. Circulation. 2009; 120(Suppl 18): S535-S.

15) Liu A, Huang J, Huang J. Generalized venous thrombosis in diabetic ketoacidosis: A case report and review. Open J Clin Med Case Rep. 2017: 1207.

16) Anderson FA, Spencer FA. Risk factors for venous thromboembolism. Circulation. 2003; $107(23$ suppl 1): I-9. doi: 10.1161/01.CIR.0000078469.07362.E6.

17) Anand SS, Wells PS, Hunt D, Brill-Edwards P, Cook D, Ginsberg JS. Does this patient have deep vein thrombosis? JAMA. 1998; 279(14): 1094-9. doi: 10.1001/jama.279.14.1094. PMID: 9546569.

18) Guyatt GH, Akl EA, Crowther M, Gutterman DD, Schuünemann HJ. Executive summary: Antithrombotic Therapy and Prevention of Thrombosis, 9th ed: American College of Chest Physicians Evidence-Based Clinical Practice Guidelines. Chest. 2012; 141(2 Suppl): 7S-47S. doi: 10.1378/chest.1412S3. PMID: 22315257, PMCID: PMC3278060.

19) Piazza G, Goldhaber SZ, Kroll A, Goldberg RJ, Emery C, Spencer FA. Venous thromboembolism in patients with diabetes mellitus. Am J Med. 2012; 125(7): 709-16. doi: 10.1016/j.amjmed.2011.12.004. PMID: 22560173, PMCID: PMC3424058.

20) Lu DY, Huang CC, Huang PH, Chung CM, Lin SJ, Chen JW, et al. Metformin use in patients with type 2 diabetes mellitus is associated with reduced risk of deep vein thrombosis: a non-randomized, pair-matched cohort study. BMC cardiovascular disorders. 2014; 14(1): 187. doi: 10.1186/1471-2261-14-187. PMID: 25510597, PMCID: PMC4274716.

21) Khorana AA, Francis CW, Culakova E, Kuderer NM, Lyman GH. Frequency, risk factors, and trends for venous thromboembolism among hospitalized cancer patients. Cancer. 2007; 110(10): 2339-46. doi: 10.1002/cncr.23062. PMID: 17918266.

22) Yamada N, Hanzawa K, Ota S, Nakamura M, Sato K, Ikura M, et al. Occurrence of deep vein thrombosis among hospitalized non-surgical Japanese patients. Annals of vascular diseases. 2015; 8(3): 203-9. doi: 10.3400/avd.oa.14-00132. PMID: 26421068, PMCID: PMC4575331.

23) Miri M, Goharani R, Sistanizad M. Deep Vein Thrombosis among Intensive Care Unit Patients; an Epidemiologic Study. Emergency. 2017; 5(1.. doi: 10.1016/j.amjcard.2003.09.057. PMID: 14715365.

24) Fekri MS, Zade MK, Fatehi S. The association of deep vein thrombosis with cancer treatment modality: chemotherapy or surgery? Iranian Red Crescent Medical Journal. 2014; 16(9).

25) Goldhaber SZ, Tapson VF, Committee DFS. A prospective registry of 5,451 patients with ultrasoundconfirmed deep vein thrombosis. Am J Cardiol. 2004; 93(2): 259-62. PMID: 14715365.

26) Keenan CR, Murin S, White RH. High risk for venous thromboembolism in diabetics with hyperosmolar state: comparison with other acute medical illnesses. J Thromb Haemost. 2007; 5(6): 1185-90. doi: 10.1111/j.1538-7836.2007.02553.x. PMID: 17403099.

27) Sun K, Wang C, Pang B, Yang Y, He W, Chen T, et al. Study on the risk factors of deep venous thrombosis in acute hospitalized stroke patients. Zhonghua Liu Xing Bing Xue Za Zhi. 2004; 25(12): 1019-23. PMID: 15769354.

28) Low FZ, Yeow RCH, Yap HK, Lim JH, editors. Study on the use of soft ankle-foot exoskeleton for alternative mechanical prophylaxis of deep vein thrombosis. 2015. IEEE International Conference on Rehabilitation Robotics. doi: 10.1109/ICORR.2015.7281264. 